\title{
Arazyme inhibits cytokine expression and upregulates skin barrier protein expression
}

\author{
IN SIK KIM ${ }^{1}$, MI JIN KIM ${ }^{1,2}$, DONG-HA SHIN ${ }^{3}$, KWANG-HEE SON ${ }^{4}$, HO-YONG PARK ${ }^{4}$ and JI-SOOK LEE ${ }^{2}$ \\ ${ }^{1}$ Department of Biomedical Laboratory Science, School of Medicine, Eulji University, Daejeon, Chungnam 301-746; \\ ${ }^{2}$ Department of Clinical Laboratory Science, Wonkwang Health Science University, Iksan, Jeonbuk 570-750; \\ ${ }^{3}$ Insect Biotech Co., Ltd., Daejeon, Chungnam 305-811; ${ }^{4}$ Industrial Bio-material Research Center, \\ Korea Research Institute of Bioscience and Biotechnology, Daejeon, Chungnam 305-806, Republic of Korea
}

Received December 3, 2012; Accepted June 6, 2013

DOI: $10.3892 / \mathrm{mmr} .2013 .1520$

\begin{abstract}
In the present study, the inhibitory effect of arazyme on allergic inflammation was investigated by evaluating the alteration of cytokine production and expression of skin barrier proteins in immune and $\mathrm{HaCaT}$ human keratinocyte cells. THP-1 human monocytic and EoL-1 human eosinophilic cells were treated with Dermatophagoides pteronissinus extract (DpE). Monocyte chemotactic protein-1 (MCP-1)/CCL2, interleukin (IL)-6 and IL-8 increased following DpE treatment and arazyme significantly blocked the increase of MCP-1, IL-6 and IL-8 expression in cell types. Secretion of MCP-1, IL-6 and IL- 8 induced by lipopolysaccharide in THP-1 cells was also inhibited by arazyme treatment. Arazyme inhibited the secretion of IL- 6 and IL- 8 due to phorbol 12-myristate 13 -acetate and calcium ionophores in human mast cells. Arazyme blocked the secretion of thymus and activation-regulated chemokine (TARC)/CCL17, MCP-1, IL-6 and IL-8 due to tumor necrosis factor- $\alpha$ (TNF- $\alpha)$ and interferon- $\gamma($ IFN- $\gamma$ ) in HaCaT cells. TNF- $\alpha$ and IFN- $\gamma$ suppressed the expression of skin barrier proteins, including filaggrin, involucrin and loricrin. By contrast, arazyme increased the expression of filaggrin, involucrin and loricrin. These results may contribute to the development of a therapeutic drug for the treatment of allergic diseases, including atopic dermatitis.
\end{abstract}

\section{Introduction}

A number of environmental and genetic factors combined with a dysregulated immune system response contributes to allergic diseases, including atopic dermatitis, asthma and allergic rhinitis (1-3). The house dust mite, Dermatophagoides

Correspondence to: Dr Ji-Sook Lee, Department of Clinical Laboratory Science, Wonkwang Health Science University, 501 Iksandaero, Iksan, Jeonbuk 570-750, Republic of Korea E-mail: jslee1216@wu.ac.kr

Key words: arazyme, allergic inflammation, cytokine, skin barrier protein pteronissinus (DpE), induces the production of immunoglobulin $\mathrm{E}$ ( $\mathrm{IgE})$, stimulates cytokine expression by activating immune cells and exploits defects in the skin barrier proteins $(4,5)$. Regulation of cytokine production is important in the pathogenesis of allergic diseases. Cytokines, including interleukin (IL)-6, IL-8 and monocyte chemotactic protein-1 (MCP-1)/CCL2, participate in the shift from acute to chronic phases of allergy and in the attraction of neutrophils and monocytes, culminating in allergic inflammation (6-8). The thymus and activation-regulated chemokine (TARC)/CCL17, which is a Th2 chemokine associated with allergy, specifically atopic dermatitis, is primarily produced in keratinocytes (9). Keratinocytes also produce skin barrier proteins, including filaggrin, involucrin and loricrin and defects in the skin barrier evoke atopic dermatitis $(10,11)$. Since the exact pathogenic mechanism of allergic diseases has not yet been determined, general therapy for atopic dermatitis depends on anti-inflammatory or immunosuppressive drugs. However, a number of drugs elicit toxic side effects.

Arazyme is a novel metalloprotease, produced and secreted in the culture medium by Aranicola proteolyticus, also known as Serratia proteamaculans, an aerobic gram-negative symbiotic bacterium that was isolated from the intestine of the spider Nephila clavata $(12,13)$. Arazyme protects against acute hepatic injury by enhancing SMP30 expression, which suppresses the transforming growth factor- $\beta$ (TGF- $\beta$ )/Smad pathway and by increasing the expression of anti-oxidant proteins (14).

The identification of new drug candidates for the treatment of allergic diseases using an in vitro screening system has previously been reported (15-17). The development of therapies for the treatment of allergic diseases has been unsuccessful thus far. Therefore, the development of a new screening system was beneficial. In the present study, the effect of arazyme on cytokine and skin barrier protein production in immune cells and skin keratinocytes was investigated, with the aim to explore arazyme therapeutically for the treatment of allergies, including atopic dermatitis.

\section{Materials and methods}

Enzyme purification. Arazyme was purified as previously described (13). Briefly, extracellular fractions were collected 
by centrifugation of the culture medium or by filtration using a $0.2 \mu \mathrm{l}$ membrane filter (Pall Life Sciences, Port Washington, NY, USA). Chromatography was performed on a DEAE-cellulose column equilibrated with $50 \mathrm{mM}$ potassium phosphate buffer ( $\mathrm{pH}$ 7.6). Bound proteins were eluted with a concentration gradient of sodium chloride ranging between 0.1 and $0.5 \mathrm{M}$ at a flow rate of $400 \mathrm{ml} / \mathrm{h}$ and each fraction was concentrated with a $10 \mathrm{kDa}$ cassette membrane (Pall Life Sciences). The protein solution was loaded at a flow rate of $20 \mathrm{ml} / \mathrm{h}$ onto a Sephadex G-75 column previously equilibrated with $50 \mathrm{mM}$ potassium phosphate buffer $(\mathrm{pH}$ 7.8). Fractions containing proteolytic activity were concentrated with the $10 \mathrm{kDa}$ cassette membrane and stored at $-20^{\circ} \mathrm{C}$.

Cell culture.The THP-1 human monocytic cell line was obtained from the American Type Culture Collection (Manassas, VA, USA). The EoL-1 human eosinophilic leukemia cell line was obtained from the Riken Cell Bank (Tsukuba, Japan). The two cell types were cultured in RPMI-1640 medium. HMC-1 human mast cells and human keratinocytic HaCaT cells were cultured in Iscove's medium and Dulbecco's modified Eagle's medium, respectively, supplemented with $10 \%$ heat-inactivated fetal bovine serum, penicillin $(100 \mathrm{U} / \mathrm{ml})$ and streptomycin $(100 \mu \mathrm{g} / \mathrm{ml})$.

Cell viability assay. Cell viability was assayed based on the conversion of 3-(4,5-dimethylthiazol-2-yl)-2,5-diphenyltetrazolium bromide (MTT) using a cell proliferation kit (Roche Korea, Seoul, Korea). THP-1, EoL-1, HMC-1 and HaCaT cells in $100 \mu$ l culture medium were seeded into a 96-well plate. Arazyme was added to the wells at a concentration ranging between 1 and $50 \mu \mathrm{g} / \mathrm{ml}$. Following incubation for $24 \mathrm{~h}$ at $37^{\circ} \mathrm{C}, 10 \mu \mathrm{l}$ MTT solution was added and incubated for $4 \mathrm{~h}$. Solubilization solution $(100 \mu \mathrm{l})$ was added to the wells. Following 24-h incubation, absorbance was measured at $550 \mathrm{~nm}$ using an ELx808 enzyme-linked immunosorbent assay (ELISA) reader (Bio-Tek Instruments Inc., Winooski, VT, USA).

ELISA. Following pre-treatment with arazyme for $30 \mathrm{~min}$, THP-1, EoL-1, HMC-1 and HaCaT cells were treated with DpE, supplied by the Korea National Arthropods of Medical Importance Resource Bank (Seoul, Korea). The concentrations of MCP-1, IL-6, IL-8, TARC and tumor necrosis factor- $\alpha$ (TNF- $\alpha$ ) in the supernatant were measured by sandwich ELISA using an OptEIA Set (BD Biosciences, San Jose, CA, USA) according to the manufacturer's instructions. The cytokine concentration was calculated using a linear-regression equation obtained from the standard absorbance values.

Western blotting. HaCaT cells were seeded into a six-well plate at a cell density of $5 \times 10^{6}$ cells $/ \mathrm{ml}$. Following treatment with TNF- $\alpha$ and interferon- $\gamma($ IFN- $\gamma$ ) in the absence or presence of arazyme, the cells were harvested and lysed in $50 \mu \mathrm{l}$ lysis buffer $(20 \mathrm{mM}$ HEPES, $400 \mathrm{mM} \mathrm{NaCl}$, $1 \mathrm{mM}$ EDTA, $1 \mathrm{mM}$ EGTA, 25\% glycerol, $1 \mathrm{mM}$ dithiothreitol, $0.1 \mathrm{mM} \mathrm{Na}_{3} \mathrm{VO}_{4}$ and protease inhibitors). Samples were centrifuged at $12,000 \mathrm{x}$ for $15 \mathrm{~min}$ at $4^{\circ} \mathrm{C}$. The protein samples (50 $\mu \mathrm{g} /$ lane) were separated by $10 \%$ sodium dodecyl sulfate-polyacrylamide gel electrophoresis and transferred to nitrocellulose filters. Blots were incubated with antibodies against filaggrin, involucrin or loricrin (Santa Cruz Biotechnology, Santa Cruz, CA, USA) and were developed using the enhanced chemiluminescence detection system (Amersham Pharmacia Biotech., Piscataway, NJ, USA). The membrane was stripped and reprobed with anti-ERK2 antibody as an internal control.

Statistical analysis. Data were presented as the mean \pm SD. The statistical differences were analyzed using a one-way ANOVA. The SPSS statistical software (version 10.0; SPSS Inc., Chicago, IL, USA) was used for statistical analysis. $\mathrm{P}<0.05$ was considered to indicate a statistically significant difference.

\section{Results}

Arazyme inhibits the secretion of MCP-1 and IL-8 in THP-1 and EoL-1 cells. A MTT-based assay was used to determine the effect of arazyme on the viability of THP-1, EoL-1, HMC-1 and HaCaT cells. As shown in Fig. 1, the survival rate of HMC-1 cells was not affected by arazyme concentration ranging between 1 and $50 \mu \mathrm{g} / \mathrm{ml}$. The viability of THP-1 and EoL-1 cells was weakly inhibited by arazyme concentration ranging between 10 and $50 \mu \mathrm{g} / \mathrm{ml}$. In $\mathrm{HaCaT}$ cells, arazyme at a concentration of $5 \mu \mathrm{g} / \mathrm{ml}$ weakly inhibited cell viability. Arazyme at concentrations ranging between 10 and $50 \mu \mathrm{g} / \mathrm{ml}$ was toxic. The secretion of MCP-1, IL-6 and IL-8 increased following treatment with an extract of DpE and lipopolysaccharide (LPS) in THP-1 cells (Fig. 2A and B). Arazyme significantly suppressed the production of MCP-1, while IL-8 increased following treatment with DpE in a dose-dependent manner, despite different inhibition depending on the cytokine type $(\mathrm{P}<0.05)$. Arazyme also inhibited the LPS-mediated increased production of MCP-1, IL-6 and IL-8 (Fig. 2B). In EoL-1 cells, DpE enhanced the expression of MCP-1, IL-6 and IL-8. MCP-1 and IL-8 expression decreased following treatment with arazyme in a dose-dependent manner (Fig. 3). IL-6 expression increased following treatment with a low concentration of arazyme, but decreased following treatment with a high concentration when compared with mite treatment alone. Alteration of IL-6 by arazyme in EoL-1 cells was similar to that in THP-1 cells (Figs. 2A and 3).

Arazyme inhibits the secretion of IL-6 and IL-8 in HMC-1 cells and the production of TARC, MCP-1, IL-6 and IL-8 in HaCaT cells. HMC-1 cells produce IL-6, IL- 8 and TNF- $\alpha$ following treatment with phorbol 12-myristate 13-acetate (PMA) and calcium ionophore (CaI). Arazyme was found to significantly inhibit the increase of IL- 6 and IL- 8 induced by PMA and $\mathrm{CaI}$ in a dose-dependent manner ( $\mathrm{P}<0.05$; Fig. 4). The cytokine production of $\mathrm{HaCaT}$ cells was also investigated. TNF- $\alpha$ and IFN- $\gamma$ increased the production of TARC, MCP-1, IL-6 and IL-8 in the cells. IL-8 was weakly blocked by arazyme, however, TARC, MCP-1 and IL-6 were markedly inhibited by arazyme. The results shown in Figs. 1-5 are consistent with the hypothesis that arazyme inhibits the cytokine production of various cells, including monocytes, 
A

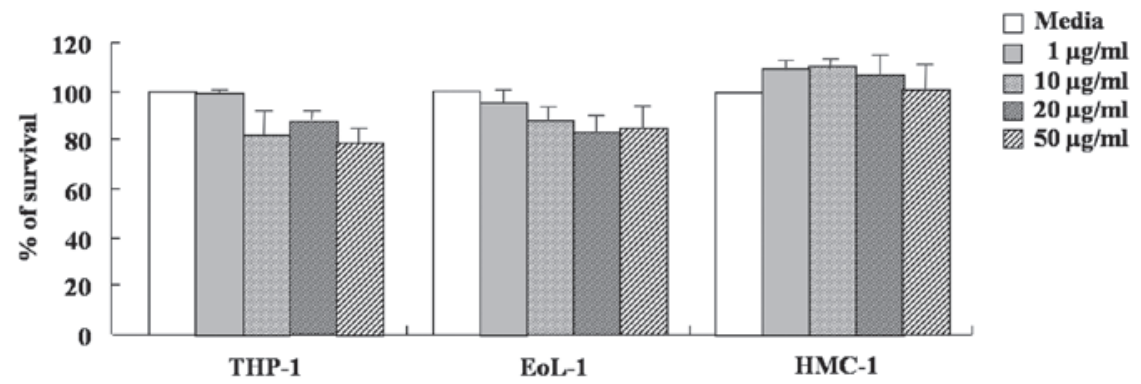

B

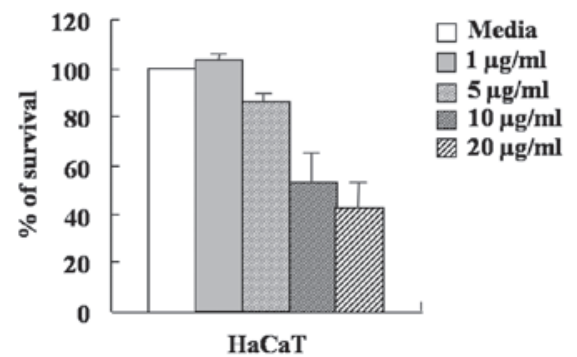

Figure 1. Effect of arazyme on survival of THP-1, EoL-1, HMC-1 and HaCaT cells. (A) THP-1, EoL-1, HMC-1 and (B) HaCaT cells were incubated in medium in the absence (medium alone) or presence of arazyme at the indicated concentrations for $24 \mathrm{~h}$. The survival rate was measured by performing the MTT-based viability assay. Data are expressed as the relative ratio to the absorbance of the untreated cells, which was set at $100 \%$ and as the mean \pm SD of three independent experiments. MTT, 3-(4,5-dimethylthiazol-2-yl)-2,5-diphenyltetrazolium bromide.

A



B

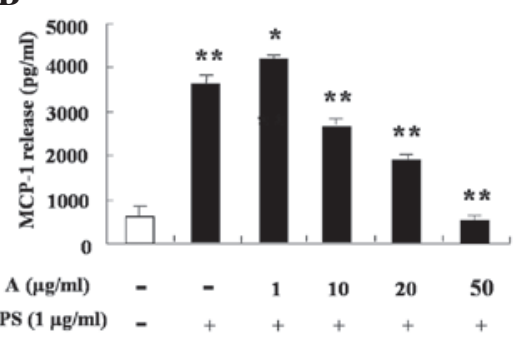



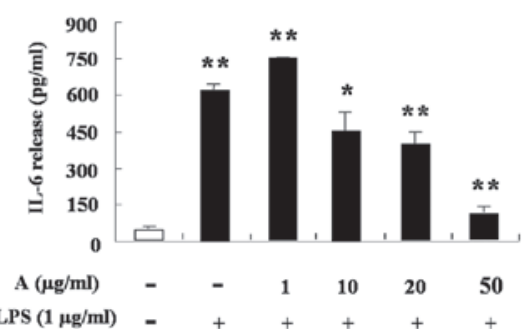



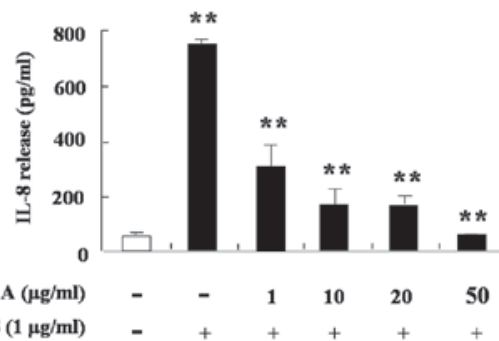

Figure 2. Arazyme inhibits the production of MCP-1, IL-6 and IL-8 increased by (A) DpE or (B) LPS in THP-1 cells. THP-1 cells were seeded in wells of 24-well plates and cultured in RPMI-1640 medium containing $0.5 \% \mathrm{FBS}$ at $37^{\circ} \mathrm{C}$ for $24 \mathrm{~h}$. Cells were pre-treated in the absence or presence of arazyme at the indicated concentrations. Cells were treated with $10 \mu \mathrm{g} / \mathrm{ml}$ mite extract for $24 \mathrm{~h}$ and the supernatant was then collected and analyzed by ELISA. Data are presented as the mean \pm SD of three independent experiments. ${ }^{*} \mathrm{P}<0.05$ and ${ }^{* *} \mathrm{P}<0.01$ was considered to indicate a statistically significant difference between the untreated vs. DpE only treated group or between the DpE only treated vs. arazyme-treated group. MCP-1, monocyte chemotactic protein-1; IL, interleukin; DpE, Dermatophagoides pteronissinus.

eosinophils, mast cells and keratinocytes, thus suggesting arazyme as a possible candidate factor for the treatment of inflammation, including allergic diseases.

Arazyme increases the expression of filaggrin, involucrin and loricrin in HaCaT cells. The extent of barrier dysfunction correlates with the degree of allergy, in particular atopic dermatitis, since the skin barrier blocks the penetration of microbes, allergens and other environmental toxins. Skin barrier proteins include filaggrin, involucrin and loricrin and are produced by keratinocytes. Therefore, the effect of arazyme on the regulation of skin barrier proteins in $\mathrm{HaCaT}$ cells was investigated. TNF- $\alpha$ and IFN- $\gamma$ treatment inhibited the expression of filaggrin, involucrin and loricrin in $\mathrm{HaCaT}$ cells (Fig. 6A). Arazyme reversed the decrease of filaggrin, involucrin and loricrin in HaCaT cells (Fig. 6B). These results indicate that arazyme 

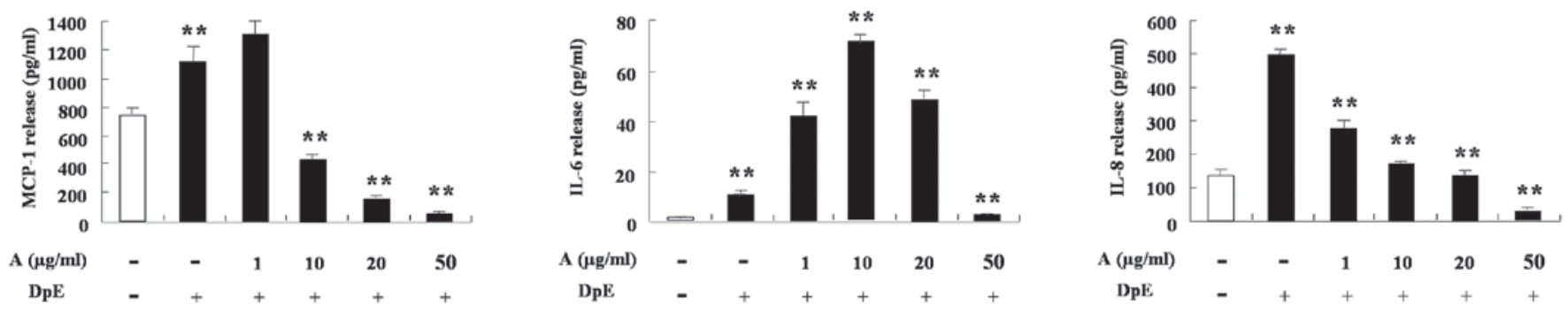

Figure 3. Arazyme inhibits the production of MCP-1, IL-6 and IL-8 increased by DpE in EoL-1 cells. EoL-1 cells were seeded in 24 well plates and cultured in RPMI- 1640 medium containing $0.5 \% \mathrm{FBS}$ at $37^{\circ} \mathrm{C}$ for $24 \mathrm{~h}$. Cells were pre-treated in the absence or presence of arazyme at the indicated concentrations. Cells were treated with $10 \mu \mathrm{g} / \mathrm{ml} \mathrm{DpE}$ for $24 \mathrm{~h}$. The supernatant was collected and analyzed by ELISA. Data are presented as the mean \pm SD of three independent experiments. ${ }^{*} \mathrm{P}<0.05$ and ${ }^{* *} \mathrm{P}<0.01$ were considered to indicate a significant difference between the untreated vs. DpE only treated group or between the $\mathrm{DpE}$ only treated vs. the arazyme-treated group. MCP-1, monocyte chemotactic protein-1; IL, interleukin; DpE, Dermatophagoides pteronissinus.
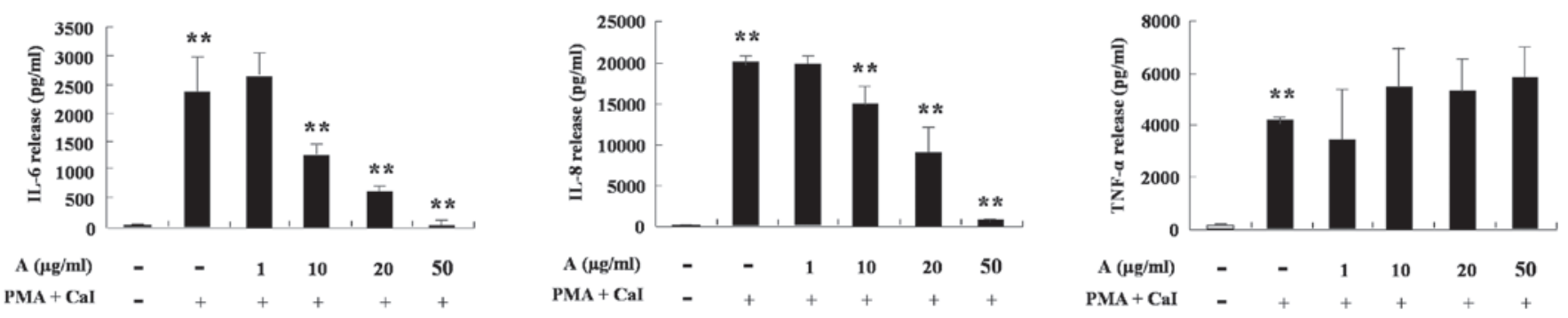

Figure 4. Arazyme blocks the production of IL-6 and IL-8 increased by PMA and CaI in HMC-1 cells. HMC-1 cells were seeded in 24-well plates and cultured in RPMI- 1640 medium containing $0.5 \% \mathrm{FBS}$ at $37^{\circ} \mathrm{C}$ for $24 \mathrm{~h}$. Cells were pre-treated in the absence or presence of arazyme at the indicated concentrations. The cells were treated with $50 \mathrm{ng} / \mathrm{ml}$ PMA and $1 \mu \mathrm{M} \mathrm{CaI}$ for $24 \mathrm{~h}$ and the supernatant was collected and analyzed by ELISA. Data are presented as the mean \pm SD of three independent experiments. " $\mathrm{P}<0.05$ was considered to indicate a significant difference between the untreated vs. the PMA+CaI only treated group or between the PMA+CaI only treated vs. the arazyme-treated group. IL, inteterleukin; MPA, phorbol 12-myristate 13-acetate; CaI, calcium ionophore.
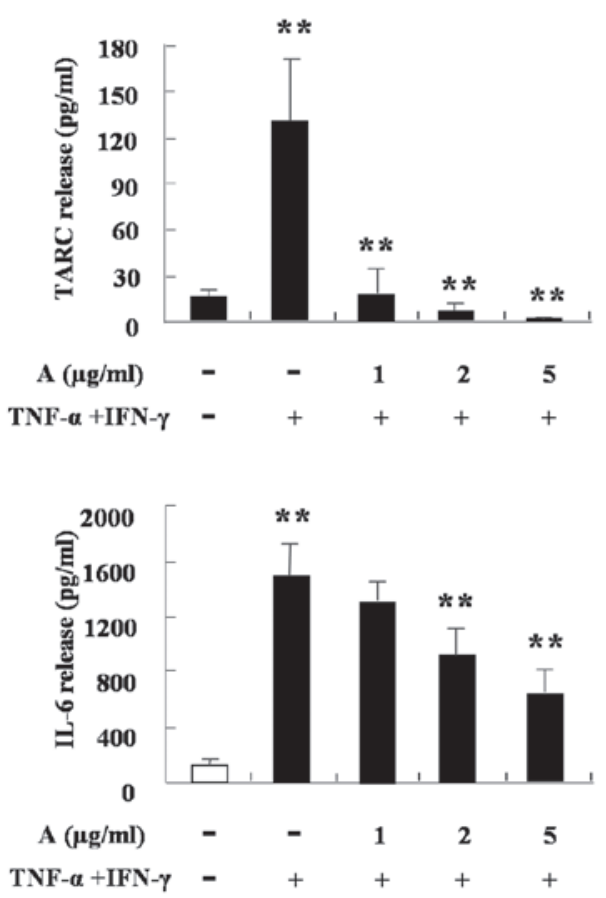


Figure 5. Arazyme suppresses the production of TARC, MCP-1 and IL-6 increased by TNF- $\alpha$ and IFN- $\gamma$ in HaCaT cells. HaCaT cells were seeded into $24-$ well plates and cultured in RPMI-1640 medium containing $0.5 \% \mathrm{FBS}$ at $37^{\circ} \mathrm{C}$ for $24 \mathrm{~h}$. The cells were pre-treated in the absence or presence of arazyme at the indicated concentrations. The cells were treated with $10 \mathrm{ng} / \mathrm{ml}$ TNF- $\alpha$ and IFN- $\gamma$ for $24 \mathrm{~h}$. The supernatant was collected and analyzed by ELISA. Data are presented as the mean \pm SD of three independent experiments. $\mathrm{P}<0.05$ and ${ }^{* *} \mathrm{P}<0.01$ were considered to indicate a significant difference between the untreated vs. the TNF- $\alpha+$ IFN- $\gamma$ only treated group or between the TNF- $\alpha+$ IFN- $\gamma$ only treated vs. the arazyme-treated group. TNF- $\alpha$, tumor necrosis factor- $\alpha$; IFN- $\gamma$, interferon- $\gamma$; TARC, thymus and activation-regulated chemokine; MCP-1, monocyte chemotactic protein-1; IL, interleukin. 
A

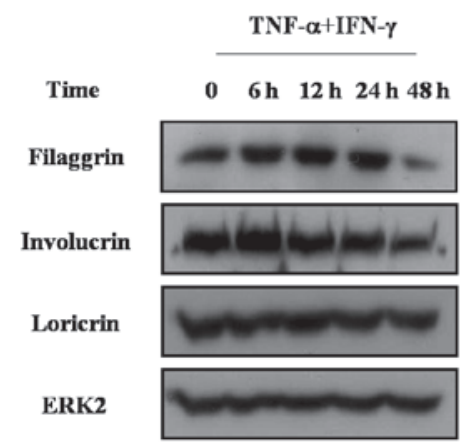

B

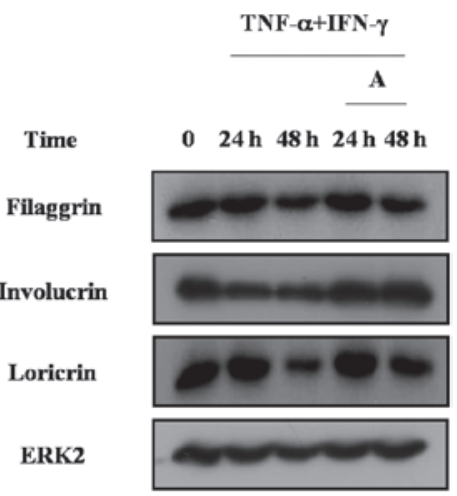

Figure 6. Arazyme increases the expression of filaggrin, involucrin and loricrin reduced by TNF- $\alpha$ and IFN- $\gamma$. (A) Serum-starved HaCaT cells were incubated with $10 \mathrm{ng} / \mathrm{ml} \mathrm{TNF-} \alpha$ and IFN- $\gamma$ for the indicated times. (B) Serum-starved HaCaT cells were pre-incubated in the absence and presence of $5 \mu \mathrm{g} / \mathrm{ml}$ arazyme for $1 \mathrm{~h}$. The cells were then incubated with $10 \mathrm{ng} / \mathrm{ml}$ TNF- $\alpha$ and IFN- $\gamma$ for 24 and $48 \mathrm{~h}$. The harvested cells were lysed and filaggrin, involucrin and loricrin were analyzed by western blot analysis. The membrane was stripped and reprobed with anti-ERK2 antibody as an internal control.TNF- $\alpha$, tumor necrosis factor- $\alpha$; IFN- $\gamma$, interferon- $\gamma$.

increases the expression of skin barrier proteins under conditions where skin barrier proteins are decreased.

\section{Discussion}

In the present study, the efficacy of arazyme as an anti-inflammatory or anti-atopic dermatitis drug was examined for the first time using human inflammatory-associated cells. Arazyme was observed to inhibit the production of MCP-1, IL-6 and IL-8 in THP- 1 and EoL-1 cells, suppress the secretion of IL- 6 and IL-8 in HMC-1 cells, reduce TARC, MCP-1, IL-6 and IL-8 in HaCaT cells and upregulate the production of filaggrin, involucrin and loricrin in $\mathrm{HaCaT}$ cells.

Arazyme is a metalloprotease and its effect on the pathogenesis of allergic inflammation is unclear, however, it is known to protect hepatocytes that have been injured by CCl4 (14). The efficacy of arazyme as an inhibitor of inflammation was determined by evaluating the alteration of cytokines in inflammatory cells and skin barrier proteins in keratinocytes. Although arazyme differentially inhibited cytokine production, depending on the effector cells, the enzyme had an inhibitory effect on cytokine production in THP-1, EoL-1, HMC-1 and HaCaT cells. Arazyme blocked IL-8 expression in all the cells used in this study and inhibited MCP-1 expression in THP-1, EoL-1 and HaCaT cells. Since MCP-1 acts as a potent chemoattractant of monocytes and IL-8 functions as an essential molecule in the survival, migration and activation of neutrophils, arazyme may inhibit the inflammatory responses by regulation of the immune responses involved in monocytes and neutrophils (18). In the present study, arazyme also suppressed IL-6 expression in HMC-1 and HaCaT cells in a dose-dependent manner. In THP-1 and EoL-1 cells, arazyme increased IL-6 expression at a low concentration and decreased the expression at a high concentration. These observations are consistent with our previous study (17), however, the mechanism remains unknown. The release of IL- 6 and IL-8 following treatment with $\mathrm{DpE}$ in our previous studies $(15,16)$ was higher than that in the present study. This inconsistency may be caused by a variety of factors, including cell culture conditions and variations in the skills of the different investigators.
However, arazyme clearly reveals an inhibitory trend of cytokine production similar to anti-inflammatory chemicals or extracts $(17,19,20)$.

Since arazyme is a protease with strong cleavage activity, it may hydrolyze pro-inflammatory molecules, including bradykinin and histamine, as previously observed $(21,22)$. This is important for determining how arazyme induces an anti-inflammatory effect. Based on the present results, a number of hypotheses were considered. Firstly, arazyme cleaves extracellular inflammatory stimulators, including mite extract, LPS, TNF- $\alpha$ and IFN- $\gamma$. Therefore, the stimulators do not transduce inflammatory signals associated with production of cytokines and skin barrier proteins. Secondly, arazyme directly cleaves cytokines, including MCP-1, IL-6, IL-8 and TARC. Arazyme also binds to a novel and as of yet unidentified receptor and tranduces an anti-inflammatory signal associated with inhibition of the cytokine production and skin barrier proteins. The exact mechanism of arazyme remains to be elucidated and is the subject of ongoing studies.

Atopic dermatitis is an allergic skin disease characterized by inappropriate epidermal-barrier function, relapsing skin inflammation and IgE-mediated sensitization to environmental allergens, including house dust mites. Filaggrin, involucrin and loricrin are major proteins that form the epidermal skin barrier and defects in the production and/or installation of these proteins is important in the pathogenesis of atopic dermatitis (23). In the present study, filaggrin, involucrin and loricrin decreased following treatment with TNF- $\alpha$ and IFN- $\gamma$ in HaCaT cells and arazyme increased expression of these molecules. Defects in skin barrier protein production evoke or aggravate atopic dermatitis by facilitating microbe penetration and contact of allergen and toxic chemicals (10). A loss of function mutation of filaggrin is associated with other allergic diseases, as well as atopic dermatitis (24). TARC is produced by keratinocytes and functions as a Th2 chemokine, which induces skin inflammation in atopic dermatitis (9). In the present study, arazyme potently decreased TARC expression in HaCaT cells. These results may indicate that arazyme alleviates the severity of atopic dermatitis by regulating the expression of TARC and skin barrier proteins in keratinocytes. 
Although drugs for allergy treatment, including atopic dermatitis, are being actively developed, steroids are broadly used as an effective drug for allergy or inflammation therapy. However, steroids elicit a variety of side effects. To investigate a new candidate for allergy treatment, the effect of arazyme derived from A. proteolyticus was investigated and arazyme was observed to induce an anti-inflammatory effect and increase the expression of filaggrin, involucrin and loricrin in keratinocytes. In conclusion, arazyme may be promising in the treatment of allergic diseases.

\section{Acknowledgements}

This research was supported by a grant from KRIBB Research Initiative Program.

\section{References}

1. Cookson WO and Moffatt MF: The genetics of atopic dermatitis. Curr Opin Allergy Clin Immunol 2: 383-387, 2002.

2. Bieber T: Atopic dermatitis. N Engl J Med 358:1483-1494, 2008.

3 . Holgate ST and Polosa R: Treatment strategies for allergy and asthma. Nat Rev Immunol 8: 218-230, 2008.

4. Marsella R and Samuelson D: Unravelling the skin barrier: a new paradigm for atopic dermatitis and house dust mites. Vet Dermatol 20: 533-540, 2009.

5. Thomas WR, Hales BJ and Smith WA: House dust mite allergens in asthma and allergy. Trends Mol Med 16: 321-328, 2010.

6. Hirano T: Interleukin 6 and its receptor: ten years later. Int Rev Immunol 16: 249-284, 1998.

7. Rossi D and Zlotnik A: The biology of chemokines and their receptors. Annu Rev Immunol 18: 217-242, 2000.

8. Shakoory B, Fitzgerald SM, Lee SA, Chi DS and Krishnaswamy G: The role of human mast cell-derived cytokines in eosinophil biology. J Interferon Cytokine Res 24: 271-281, 2004.

9. Tokura Y: Extrinsic and intrinsic types of atopic dermatitis. J Dermatol Sci 58: 1-7, 2010.

10. De Benedetto A, Agnihothri R, McGirt LY, Bankova LG and Beck LA: Atopic dermatitis: a disease caused by innate immune defects. J Invest Dermatol 129: 14-30, 2009.

11. Kim BE, Howell MD, Guttman-Yassky E, Gilleaudeau PM, Cardinale IR, Boguniewicz M, Krueger JG and Leung DY: TNF- $\alpha$ downregulates filaggrin and loricrin through c-Jun $\mathrm{N}$-terminal kinase: role for TNF- $\alpha$ antagonists to improve skin barrier. J Invest Dermatol 131: 1272-1279, 2011.
12. Bersanetti PA, Park HY, Bae KS, Son KH, Shin DH, Hirata IY, Juliano MA, Carmona AK and Juliano L: Characterization of arazyme, an exocellular metalloprotease isolated from Serratia proteamaculans culture medium. Enzyme Microb Technol 37: 574-581, 2005.

13. Kwak J, Lee K, Shin DH, Maeng JS, Park DS, Oh HW, Son KH, Bae KS and Park HY: Biochemical and genetic characterization of arazyme, an extracellular metalloprotease produced from Serratia proteamaculans HY-3. J Microbiol Biotechnol 17: 761-768, 2007.

14. Park JK, Jeong DH, Park HY, Son KH, Shin DH, Do SH, Yang HJ, Yuan DW, Hong IH, Goo MJ, Lee HR, Ki MR, Ishigami A and Jeong KS: Hepatoprotective effect of Arazyme on CCl4-induced acute hepatic injury in SMP30 knock-out mice. Toxicology 246: 132-142, 2008.

15. Lee JS, Kim IS, Ryu JS and Yun CY: House dust mite, Dermatophagoides pteronissinus increases expression of MCP-1, IL-6 and IL-8 in human monocytic THP-1 cells. Cytokine 42: 365-371, 2008.

16. Lee JS, Kim IS, Ryu JS and Yun CY: House dust mite, Dermatophagoides pteronissinus increases expression of MCP-1, IL-6 and IL-8 in human eosinophilic leukemia EoL-1 cells. Animal Cells Syst 13: 391-397, 2009.

17. Kim IS, Song GY, Kim DH, Cho SH, Yun CY and Lee JS: Effect of (E)-2-(3,4-dimethoxy phenyl)-4-oxo-4H-chromen-7-yl-3-(3,4-dimethoxyphenyl) acrylate on the development of atopic dermatitis-like lesions. Life Sci 91: 338-344, 2012.

18. Murphy PM, Baggiolini M, Charo IF, Hébert CA, Horuk R, Matsushima K, Miller LH, Oppenheim JJ and Power CA: International union of pharmacology. XXII. Nomenclature for chemokine receptors. Pharmacol Rev 52: 145-176, 2000.

19. Yang EJ, Lee JS, Song BB, Yun CY, Kim DH and Kim IS: Anti-inflammatory effects of ethanolic extract from Lagerstroemia indica on airway inflammation in mice. J Ethnopharmacol 136: 422-427, 2011

20. Lee JS, Kim IS, Ryu JS, Kim JH, Kim JS, Kim DH and Yun CY: The inhibitory effect of Duchesnea chrysantha extract on the development of atopic dermatitis-like lesions by regulating $\mathrm{IgE}$ and cytokine production in Nc/Nga mice. Phytother Res 26: 284-290, 2012.

21. Hauck G: Proceedings: Vitalmicroscopic investigations of the effects of thrombin, a snake venom enzyme and histamine effect on the mesenteric microvasculature of rabbit and cat. Arzneimittelforschung 26: 1233, 1976.

22. Wolz RL and Bond JS: Phe5(4-nitro)-bradykinin: a chromogenic substrate for assay and kinetics of the metalloendopeptidase meprin. Anal Biochem 191: 314-320, 1990.

23. Candi E, Schmidt R and Melino G: The cornified envelope: a model of cell death in the skin. Nat Rev Mol Cell Biol 6: 328-340, 2005.

24. Holloway JW, Yang IA and Holgate ST: Genetics of allergic disease. J Allergy Clin Immunol 125 (2 Suppl 2): S81-S94, 2010. 